\title{
Correction to: Safety and effectiveness of long-term use of darbepoetin alfa in non-dialysis patients with chronic kidney disease: a post-marketing surveillance study in Japan
}

\author{
Tetsuhiro Tanaka ${ }^{1} \cdot$ Masaomi Nangaku ${ }^{1} \cdot$ Enyu Imai ${ }^{2} \cdot$ Yoshiharu Tsubakihara $^{3} \cdot$ Masatoshi Kamai $^{4} \cdot$ Michihito Wada $^{5}$. \\ Shinji Asada ${ }^{5} \cdot$ Tadao Akizawa $^{6}$
}

Published online: 23 January 2019

(C) Japanese Society of Nephrology 2019

\section{Correction to: Clinical and Experimental Nephrology https://doi.org/10.1007/s10157-018-1632-9}

In the original publication of the article, two sentences in the "Results" section were published incorrectly. The corrected texts are provided below:

1. In the first paragraph of the section "Effectiveness", 10th line should read as "The administered dose of darbepoetin (mean $\pm \mathrm{SD}, \mu \mathrm{g}$ ) in the effectiveness analysis".

2. In the fourth paragraph of the section "Effectiveness", 1 st line should read as "Female patients or those with advanced age...baseline systolic blood pressure $\geq 130$ mmHg".
Publisher's Note Springer Nature remains neutral with regard to jurisdictional claims in published maps and institutional affiliations.

The original article can be found online at https://doi.org/10.1007/ s10157-018-1632-9.

Shinji Asada

shinji.asada@kyowa-kirin.co.jp

1 Division of Nephrology and Endocrinology, The University of Tokyo Graduate School of Medicine, Bunkyo-ku, Tokyo, Japan

2 Internal Medicine of Nakayamadera Imai Clinic, Takarazuka, Hyogo, Japan

3 Graduate School of Health Care Sciences, Jikei Institute, Yodogawa-ku, Osaka, Japan

4 Pharmacovigilance Department, Kyowa Hakko Kirin Co., Ltd., Chiyoda-ku, Tokyo, Japan

5 Medical Affairs Department, Kyowa Hakko Kirin Co., Ltd., Otemachi Financial City Grand Cube, 1-9-2 Otemachi, Chiyoda-ku, Tokyo 100-0004, Japan

6 Showa University, Shinagawa-ku, Tokyo, Japan 